\title{
Correction to: Comparison of 12 surrogates to characterize CT radiation risk across a clinical population
}

\author{
Francesco Ria ${ }^{1,2}$ (D) Wanyi Fu ${ }^{1} \cdot$ Jocelyn Hoye ${ }^{1} \cdot$ W. Paul Segars ${ }^{1} \cdot$ Anuj J. Kapadia ${ }^{1}$. Ehsan Samei ${ }^{1,2,3}$ \\ Published online: 31 March 2021 \\ (C) European Society of Radiology 2021
}

\section{Correction to: European Radiology} https://doi.org/10.1007/s00330-021-07753-9

The original version of this article, published on 23 February 2021, unfortunately contained a mistake. The following correction has therefore been made in the original: The affiliations of Wanyi Fu, Jocelyn Hoye, W. Paul Segars and Anuj J. Kapadia were incorrect. The corrected affiliations are given above. The original article has been corrected.

Publisher's note Springer Nature remains neutral with regard to jurisdictional claims in published maps and institutional affiliations.

The online version of the original article can be found at https://doi.org/ 10.1007/s00330-021-07753-9

Francesco Ria

francesco.ria@duke.edu

1 Carl E. Ravin Advanced Imaging Labs, Duke University Health System, 2424 Erwin Road, Suite 302, Durham, NC 27710, USA

2 Clinical Imaging Physics Group, Duke University Health System, 2424 Erwin Road, Suite 302, Durham, NC 27710, USA

3 Medical Physics Graduate Program, Departments of Radiology, Physics, Biomedical Engineering, and Electrical and Computer Engineering, Duke University, 2424 Erwin Road, Suite 302, Durham, NC 27710, USA 